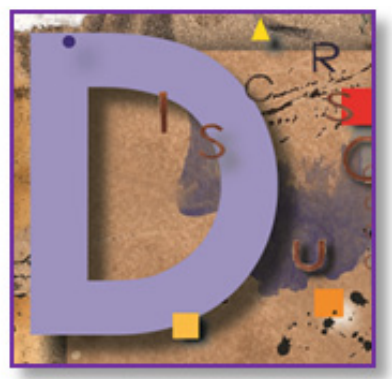

\title{
O FANTASMA ESTRUTURALISTA E A ANÁLISE DE DISCURSO CRÍTICA
}

Alexandre Costa $^{1}$

DISCURSOS CONTEMPORÄNEOS

EM

ESTUDO

ISSN 2237-7247

Neste artigo, discutimos a presença e a importância da epistemologia estruturalista e suas consequências teórico-metodológicas para todas as áreas e abordagens da Linguística, inclusive para aquelas que tratam do uso da linguagem. Localizamos sua influência na reflexão de autores das Ciências Humanas em que os estudos do discurso buscam subsídios teóricos e as correntes de pesquisa que se mantêm ainda no escopo dessa herança. Concluímos que a Análise de Discurso Crítica é uma das abordagens que parece manter-se nessa epistemologia.

Palavras-chave: Linguística. Epistemologia. Estruturalismo. ADC.

\section{Introdução}

O aparente insucesso da aplicação dos métodos estruturalistas nos níveis superiores ao da frase, no âmbito da Linguística, bem como a "ressaca" de sua transferência maciça a outras ciências sociais causaram uma profunda desvalorização dessa base epistemológica nos estudos da língua e da linguagem. Atualmente, a presença da abordagem estruturalista na Linguística é quase fantasmagórica. Seria preciso avaliar a que aspecto dos procedimentos de exclusão discursiva ela foi conjurada: se ao tabu do objeto, se ao ritual da circunstância ou se ao direito privilegiado ou exclusivo de fala. O certo é que, atualmente, o estruturalismo está na periferia do espaço da vontade de verdade dos estudos linguísticos ${ }^{2}$.

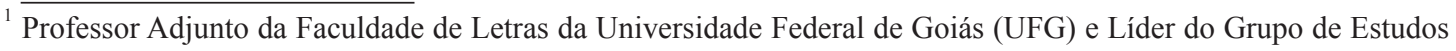
Críticos e Aplicados ao Discurso Religioso (NOUS - UFG/CNPq).

${ }^{2}$ Em sua discussão da exclusão discursiva, Foucault descreve os aspectos do que chama de primeiro procedimento: "Sabe-se que não se tem o direito de dizer tudo, que não se pode falar de tudo em qualquer circunstância, que qualquer um, enfim, não pode falar de qualquer coisa". Nas páginas seguintes, o autor define a vontade de verdade pela "oposição entre falso e verdadeiro". Aliás, ele parece fazê-lo em um viés estrutural, o que não é estranho em um livro cujo título é $A$ ordem do discurso (FOUCAULT, 1996, 13-14).
} 
Apesar disso, parece que a epistemologia estruturalista e suas consequências teóricometodológicas continuam presentes e ainda são importantes para todas as áreas e abordagens da Linguística, inclusive para aquelas que tratam do uso da linguagem. Isso não apenas porque seja possível localizar sua influência na reflexão de autores das Ciências Humanas em que os estudos do discurso e da enunciação buscam subsídios teóricos, mas, sobretudo, porque dependemos de pesquisas que se mantêm muito próximas dessa herança.

Esse é o caso das duas grandes abordagens teórico-metodológicas dos estudos gramaticais, que não são nomeadas explicitamente como estruturalistas: o gerativismo e o funcionalismo. Ambas, na verdade, assumem parcialmente seu viés estruturalista, ainda que em direções explicativas inversas.

O gerativismo busca, em suas análises, sistemas linguísticos internos (ou profundos) que são constitutivos da diversidade superficial da linguagem tentando encontrar as estruturas de cada língua e, nelas, a gramática universal. Um exemplo perfeito do continuum entre o estruturalismo e o gerativismo é a seguinte definição da noção de gramática encontrada em um texto de divulgação científica (PERINI, 2006, p. 23, grifo nosso): “[...] chama-se gramática um sistema de regras, unidades e estruturas que o falante de uma língua tem programado em sua memória e que lhe permite usar sua língua". Neste caso, inclusive, a noção de estrutura está desenvolvida pela metáfora da "programação", implicando um nível de realidade inconsciente que se manifesta no uso.

O funcionalismo, por seu turno, apesar de não estar comumente identificado com a pesquisa de origens profundas para os dados que constrói, funda-se também nas noções de sistema e de estrutura. Essa manutenção da construção de uma realidade interna da linguagem, no entanto, à diferença do gerativismo, adota como perspectiva de análise, a interiorização de estruturas e não a sua exteriorização:

[...] [essa abordagem] é funcional porque não separa o sistema linguístico e suas peças das funções que têm de preencher, e é dinâmica porque reconhece, na instabilidade da relação entre estrutura e função, a força dinâmica que está por detrás do constante desenvolvimento da linguagem (NEVES, 2004, p. 3, grifo nosso).

As duas abordagens, portanto, constroem modelos estruturais para seus dados e têm de produzi-los com base em recortes empíricos do uso da linguagem. Fazem-no, no entanto, em direções analíticas diferentes, que privilegiam, respectivamente, a estabilidade e a instabilidade estrutural. Por isso, a segunda é o viés mais comum da manutenção do estruturalismo nos estudos da linguagem, ainda que modelos cognitivistas possam estar mais próximos à primeira. Por decorrência, é razoável prever que todas as vertentes da Linguística que se baseiam nas descrições das gramáticas funcionais devam participar, em alguma medida, de sua epistemologia. Desse modo, a constituição de objetos ou níveis de análise que incluem, por exemplo, mecanismos interfrásticos, processos de referenciação, tipos e sequências de texto deveria produzir esse tipo de assimilação. É nesse nível de relação que, aparentemente, 
encontram-se as pesquisas em Linguística Aplicada, em Linguística Textual e até mesmo em Análise do Discurso. Em outras palavras, se as áreas da Linguística que se concentram no estudo do uso da linguagem valem-se das descrições e de explicações gramaticais funcionais, devem, em alguma medida, incorporar também o viés epistemológico estruturalista.

A Linguística Textual, por exemplo, refere-se a si mesma como uma "gramática do texto" que dialogou com a Semântica, passou depois pelas viradas pragmática e cognitivista e chegou, finalmente, à perspectiva sociocognitiva-interacionista. Na última fase, que poderia ser chamada de "virada discursiva", essa disciplina tenta articular a dialogia bakhtiniana a modelos cognitivos e a descrições gramaticais ( $\mathrm{KOCH}, 2004$, p. 32-33, grifo nosso):

Dentro desta concepção, amplia-se, mais uma vez, a noção de contexto, tão cara à Linguística Textual. Se, inicialmente, quando das análises transfrásicas, o contexto era visto apenas como co-texto (segmentos textuais precedentes e subsequentes ao fenômeno em estudo), tendo, quando da introdução da pragmática, passado a abranger primeiramente a situação comunicativa e, posteriormente, o entorno sócio-histórico-cultural, representado na memória por modelos cognitivos, ele passa a constituir agora a própria interação e seus sujeitos: o contexto constrói-se, em grande parte, na própria interação. Portanto, na concepção interacional (dialógica), [...] [a] produção de linguagem constitui atividade interativa altamente complexa de produção de sentidos, que se realiza, evidentemente, com base nos elementos linguisticos presentes na superficie textual e na sua forma de organização [...].

O viés estruturalista do trecho citado é reconhecível não apenas porque os elementos linguísticos presentes na superfície textual são analisados com modelos subsidiados pela gramática funcional, mas também pela pressuposição de outras superfícies. A conjugação de tais superfícies parece significar o relacionamento estrutural entre texto, contexto e cognição. Além disso, a tardia assunção da perspectiva interacionista não deve escapar a esse jogo de homologias, sob pena de destruir o modelo dessa dinâmica de instanciações recíprocas dos elementos de cada uma das superfícies: a linguagem estrutura a cognição, que estrutura a interação, que volta a estruturar a linguagem e assim sucessivamente. Nessa linha, a própria noção de dialogia, portanto, apenas pode ser descrita e explicada pelos aparatos teóricometodológicos da Linguística Textual se puder ser estruturada.

Assim, ainda que seja possível supor que a virada discursiva dessa disciplina tenha sido unilateral, isso é improvável. Sua relação com as análises do discurso teve de ser produzida com base em uma intercompreensão epistemológica mínima, como a expressa em categorias como posição de sujeito e sistema de enunciados, as quais permitem indicar a presença terminológica do estruturalismo. É sabido que as palavras "posição" e "sistema" constam do vocabulário dessa epistemologia, mas devemos questionar também se, nas análises do discurso, a perspectiva estruturalista é condição de seu uso operacional. Nesse caso, a noção de valor, tão cara à linguística clássica, deveria estar implicada na recuperação 
dessas categorias teóricas: o valor de um elemento discursivo corresponderia à sua posição em um sistema de diferenças. Na Análise de Discurso Crítica, que incorpora explicitamente as contribuições das linguísticas do texto e da gramática funcional, esse parece ser o caso. Com relação à Análise do Discurso de linha francesa, talvez baste lembrar que seus comentadores têm reconhecido, reiteradamente, a importância do cruzamento das obras de Saussure, de Freud e de Marx com as releituras de Pêcheux, de Lacan e de Althusser, para a formação de seu "solo epistemológico" (GREGOLIN, 2004, p. 13). Além disso, é fartamente conhecida a crítica à sua assunção do efeito de assujeitamento dos agentes sociais pelas estruturas, posição abandonada posteriormente.

É importante lembrar, entretanto, que as análises do discurso (quase) sempre se fizeram acompanhar pela também assustadora noção de acontecimento, um limite ontológico da epistemologia estruturalista que será discutido a seguir. Na verdade, a relação entre estrutura e acontecimento, à exceção de abordagens estruturalistas e gerativistas da fonologia e da gramática, não é totalmente estranha a todas as áreas da Linguística, que se pautam pela inclusão do uso da linguagem em sua empiria. Nesse sentido, a reflexão sobre a manutenção do estruturalismo como um dos paradigmas dos estudos linguísticos deve retomar a eventicidade do nosso objeto, o insolúvel reflexo do fantasma estruturalista.

\section{A ontologia bakhtiniana e suas indicações epistemológicas: o estruturalismo dialógico}

Por derivação do que já foi dito, tentaremos agora estabilizar e verticalizar essa discussão epistemológica por meio de uma polêmica hermenêutica da obra de Bakhtin. Nela, encontramos tanto a defesa de uma objetividade inevitável, ainda que precária, quanto a afirmação de uma ética inapreensível, ainda que absoluta. Em outras palavras, buscaremos sustentar que o filósofo russo situa a validade da ética no devir e a do conhecimento na objetividade.

A problemática ontológico-epistemológica bakhtiniana, enfrentada transversalmente em diversos textos, foi explicitamente definida pelo autor em Para uma filosofia do ato ${ }^{3}$. $\mathrm{Na}$ obra - escrita antes de todas as outras, mas só revelada e publicada muito mais tarde ${ }^{4}-$, o autor parte do princípio de que as atividades culturais (ciência, filosofia, literatura, história etc.) "estabelecem uma cisão entre o conteúdo ou sentido de um dado ato-atividade e a realidade histórica do seu ser, a real e única experiência dele", porque não são capazes de tratar da inalcançável "transitividade e aberta eventicidade do Ser" (BAKHTIN, [1993] s/d, p. 2). A superação do corte entre o teórico e o real único e concreto seria "totalmente sem esperança", uma vez que o vivido nunca pode ser totalmente objetivado (BAKHTIN, [1993] s/d, p. 28):

\footnotetext{
${ }^{3}$ Neste artigo, utilizamos a fotocópia da edição brasileira inédita, traduzida da edição americana de 1993. Já há, no entanto, uma edição brasileira publicada por Pedro \& João Editores (BAKHTIN, 2010).

${ }^{4}$ Segundo o prefácio de Michael Holquist, Bakhtin escondera este texto e mais outro, escritos no início de sua carreira, por temor à repressão do stalinismo soviético. No final de sua vida, revelou o segredo a alguns discípulos que encontraram os manuscritos. Apesar de estarem já danificados, foram suficientes para uma compilação que resultou em sua publicação.
} 


\begin{abstract}
Reconhecemos como infundadas e essencialmente sem esperança todas as tentativas de orientar uma filosofia primeira (a filosofia do Ser-evento unitário e único) em relação ao aspecto do conteúdo-sentido, ou do produto objetivado, fazendo-se abstração do ato-ação real, único, e de seu autor - aquele que está pensando teoricamente, contemplando esteticamente e agindo eticamente. É apenas de dentro do ato realmente executado, que é único, integral e unitário em sua responsabilidade, que nós podemos encontrar uma abordagem ao Ser único e unitário em sua realidade concreta. Uma filosofia primeira só pode orientar-se em relação a esse ato realmente executado.
\end{abstract}

Ainda que a lógica do raciocínio de Bakhtin seja impecável, merece a pena da paráfrase: o sujeito que existe nos processos do mundo é concreto, único, e sua realidade é a eventicidade permanente. $\mathrm{O}$ conhecimento estético ou teórico, qualquer que seja a sua forma, é a contemplação disso: uma abstração que é incapaz de reproduzir a concretude, a unicidade e a transitividade do real. Estabelecido esse axioma, o autor passa a discutir as implicações e os limites do conhecimento objetivo para a definição de um sistema ético. Bakhtin está interessado em desbancar a imaterialidade da ética abstrata e universal de Kant e em afirmar o não álibi na existência, a responsabilidade constitutiva da realidade processual do Ser. Como ele mesmo assume, seu tratamento disso é fenomeno lógico ${ }^{5}$, uma vez que tal problemática não cabe na objetividade (não se presta à estruturação). Em outras palavras, Bakhtin nos diz que o real, em última análise, é irredutível à sua representação objetiva, sobretudo pela implicação constitutiva dos sujeitos no mundo ${ }^{6}$.

Sem desconsiderar os riscos da afirmação seguinte, diremos que, apesar dessa assunção ontológica, Bakhtin buscará objetivar o real em seus trabalhos subsequentes. Mesmo considerando a transitividade da materialidade espaço-temporal da vida e suas implicações existenciais de enfrentamento do mundo como possibilidade, ele também utilizará princípios de descrição objetiva dos processos da realidade. Nossa leitura do raciocínio do autor, salvo melhor juízo, estabelece uma derivação lógica aparentemente inescapável: se a transitividade do Ser é inapreensível, toda pesquisa objetiva será redutora. Em outras palavras, toda pesquisa científica tratará apenas parcialmente da complexidade, sendo suas demandas de rigor e de validade relativas ao equilíbrio da relação entre as descrições reducionistas e as derivações explicativas do real. Nesse sentido, a abordagem bakhtiniana será relacionada com a discussão subsequente com base nas seguintes derivações axiomáticas:

a) A realidade do Ser é sempre o devir, o processo.

b) O discurso teórico é sempre uma objetivação parcial dessa realidade.

\footnotetext{
${ }^{5}$ Quer dizer, busca apreender a experiência vivida da subjetividade, em detrimento da objetividade; é, portanto, apenas indicativa de um tipo de experiência que deve ser verificada em ato.

${ }^{6}$ Em certa medida, Bakhtin antecipa a polêmica entre existencialistas, marxistas e estruturalistas, à diferença de que ele mesmo ocupa todos os lugares da polêmica!
} 
c) Todo e qualquer nível de objetivação não está isento em relação às suas limitações, ou seja, deve reconhecer operacionalmente sua precariedade.

d) A produtividade de qualquer abordagem objetivante resulta dos níveis e das relações que possam construir para o real, de acordo com seus propósitos.

e) Todo dispositivo teórico-metodológico, ou seja, objetivo será sempre mais produtivo quanto menos depender dos aspectos do real que exclui.

A transição da impossibilidade da objetivação do devir para o tratamento teórico da linguagem se produz no pensamento bakhtiniano por meio da noção de dialogia ou dialogismo. A constituição da relação de diálogo como fundadora de todos os aspectos e circunstâncias do uso da linguagem é a condição de sua objetivação. Assim, nos trabalhos de Bakhtin, a dialogia é o princípio constitutivo e o modo real de funcionamento da linguagem (e de todo comportamento humano). Na interpretação de Fiorin (2006, p. 167), esta é a base do raciocínio bakhtiniano:

\begin{abstract}
Os homens não têm acesso direto à realidade, pois nossa relação com ela é sempre mediada pela linguagem. [...] Isso quer dizer que o real se apresenta para nós semioticamente, o que implica que nosso discurso não se relaciona diretamente com as coisas, mas com outros discursos, que semiotizam o mundo. Essa relação entre os discursos é o dialogismo. Como se vê, se não temos relação com as coisas, mas com os discursos que lhes dão sentido, o dialogismo é o modo de funcionamento real da linguagem, uma vez que [está marcado, mesclado, refratado, mobilizado, infiltrado e emparelhado com outros discursos].
\end{abstract}

Desse modo, os enunciados é que são as unidades reais da comunicação. Deles resultam as palavras e as orações como unidades da língua. Dos sentidos únicos dos enunciados, palavras e orações surgem já como abstrações que produzem a estabilização de significados, inclusive formais, e que constituem a língua. Na perspectiva bakhtiniana, o erro do objetivismo abstrato é saltar a etapa da descrição das singularidades dialógicas, ou desprezá-las, tomando como o real da linguagem as abstrações do sistema linguístico construído. Em outras palavras, é a objetivação das tipologias dialógicas que permite, de fato, a abstração da língua e, mais importante ainda, que condiciona o entendimento do funcionamento da linguagem.

Dessas considerações depende a compreensão da perspectiva de objetivação teórica do autor russo, da qual inferiremos a emergência dos conceitos de estrutura e prática em sua obra, por meio de sua definição da noção de gênero discursivo (BAKHTIN, 1997, p. 279-281, grifo do autor): 
Todas as esferas da comunicação humana, por mais variadas que sejam, estão sempre relacionadas com a utilização da língua. Não é de surpreender que o caráter e os modos dessa utilização sejam tão variados como as próprias esferas da atividade humana [...]. A utilização da língua efetuase em forma de enunciados (orais e escritos), concretos e únicos, que emanam dos integrantes duma ou doutra esfera da atividade humana. O enunciado reflete as condições específicas e as finalidades de cada uma dessas esferas, não só por seu conteúdo (temático) e por seu estilo verbal, ou seja, pela seleção operada nos recursos da língua - recursos lexicais, fraseológicos e gramaticais -, mas também, e sobretudo, por sua construção composicional. Esses três elementos (conteúdo temático, estilo e construção composicional) fundem-se indissoluvelmente no todo do enunciado, e todos eles são marcados pela especificidade de uma esfera da comunicação. Qualquer enunciado considerado isoladamente é, claro, individual, mas cada esfera de utilização da língua elabora seus tipos relativamente estáveis de enunciados, sendo isso que denominamos gêneros do discurso.

Ainda que o autor frise a relatividade da estabilidade dos gêneros, ou seja, uma instabilidade relativa, sua noção de gênero discursivo pode ser considerada como uma objetivação da real eventicidade dos enunciados. Além disso, em seus princípios de tratamento do objeto, são visíveis certos procedimentos estruturais: a análise por meio da decomposição e da composição, verificadas pela substituição e pela distribuição dos elementos encontrados. De fato, tal tratamento operativo não está totalmente explícito, mas é derivável das categorias de classificação que ele apresenta. A relação que o autor estabelece entre esferas e gêneros, por um lado, e entre gêneros e seus elementos, por outro, parecem estar em conformidade com a clássica explicação de Benveniste ${ }^{7}$ sobre os níveis de análise linguística.

À primeira vista, no entanto, esse reconhecimento seria estranho ao trabalho de Bakhtin, uma vez que ele critica a abordagem saussuriana ${ }^{8}$. Essa associação poderia parecer uma aberração para muitos pesquisadores bakhtinianos,sobretudo, pelo fato de o estruturalismo ter sido associado a crenças de que a realidade é determinada unilateralmente por estruturas que são sempre redutíveis a outras estruturas mais profundas até o limite de uma Razão Universal, determinante tanto do real, quando da cognição e dada a priori ${ }^{9}$. No entanto, a coerência entre as considerações ontológicas de Bakhtin e seu uso dos procedimentos estruturalistas na definição da noção de gênero discursivo ancora-se em uma diferença fundamental entre sua abordagem e as abordagens estruturalistas tradicionais. A crítica bakhtiniana ao objetivismo

\footnotetext{
${ }^{7}$ Benveniste (1995; 1989).

${ }^{8} \mathrm{Ou}$, mais explicitamente, pela desconsideração da dialogia como princípio constitutivo da linguagem, em todos os seus níveis, mas, sobretudo, pela desconsideração do enunciado como seu elemento fundamental em lugar do signo (a palavra).

${ }^{9}$ Essa é a assunção kantiana contra a qual Bakhtin se contrapõe em Para uma filosofia do ato, a qual, em princípio, foi depois assumida pelo mais famoso dos estruturalistas, o antropólogo Lévi-Strauss, e pelo mais proeminente gerativista, Noam Chomsky.
} 
abstrato é relativa à redução do todo enunciativo à sua parte estrutural, que deveria ser obtida pela análise do enunciado concreto e irrepetível. O concreto em Bakhtin é o enunciado e jamais a estrutura.

Assim, trata-se de uma divergência ontológica e não epistemológica. Uma vez aceita a fundamentação do que chamamos de estruturalismo dialógico bakhtiniano, a noção de gênero discursivo pode ser desenvolvida mais e mais explicitamente nestes termos: tratar uma esfera social como um sistema (uma estrutura) de gêneros e, disso, compor a sociedade como um sistema de esferas sociais. Ou, noutra direção, analisar uma sociedade como um sistema de esferas sociais, e os sistemas das esferas sociais pelo valor de seus gêneros: pensar em cada gênero como um elemento de uma esfera pelas relações de diferença que estabelece com os outros gêneros da mesma esfera, com sua composição, decomposição e substituição de temas, de estilos e de estrutura composicional. É preciso salientar, ainda uma vez mais, que o estruturalismo bakhtiniano é um modelo explicativo, cujo axioma ontológico prevê a força constitutiva da dialogia derivada da eventicidade que se manifesta nas práticas. Essa é a direção da sua análise estrutural.

De acordo com a proposta de Eco, expressa em A estrutura ausente (1997), a abordagem de Bakhtin é uma espécie de estruturalismo metodológico. Nessa acepção, as estruturas não estão dadas desde sempre nem determinam as práticas unilateralmente; são modelos aplicados aos objetos que podem ou não coincidir com a sua realidade ontológica, mas que produzem uma construção compreensiva da empiria. Na abordagem de Bakhtin (1997, p. 282), a relação entre práticas e estruturas é dialógica: "A língua penetra na vida através dos enunciados concretos que a realizam, e é também através dos enunciados concretos que a vida penetra na língua". Além disso, apesar de permitir a descrição da sociedade como um sistema de sistemas - de esferas sociais e de gêneros discursivos - Bakhtin está mais preocupado com o processo dialógico do que com a hierarquia estrutural. Mesmo em Marxismo e filosofia da linguagem, quando se refere mais detidamente à questão das classes sociais, é ainda na dialogia ${ }^{10}$ do signo que se ancoram suas análises, como sugerem as seguintes considerações sobre "a ordem metodológica para o estudo [dos elementos] da língua" (BAKHTIN, 2004, p. 124) ${ }^{11}$ :

1. As formas e os tipos de interação verbal em ligação com as condições concretas em que se realiza.

2. As formas das distintas enunciações, dos atos de fala isolados, em ligação estreita com a interação de que constituem os elementos, isto é, as categorias de atos de fala na vida e na criação ideológica que se prestam a uma determinação pela interação verbal.

3. A partir daí, exame das formas da língua na sua interpretação linguística habitual.

${ }^{10}$ Dizemos dialógico porque esse termo indica, em Bakhtin, uma relação de responsividade entre todos os elementos da realidade e da linguagem. No entanto, haverá também uma relação dialética constante porque as práticas estão sempre a desestabilizar ou a desconstruir as estruturas, o que significa contraditar sua estabilidade. Novas estruturações sincrônicas são as sucessivas sínteses.

${ }^{11}$ E completa: "É nessa mesma ordem que se desenvolve a evolução real da língua: as relações sociais evoluem (em função das infraestruturas), depois a comunicação e a interação verbais evoluem no quadro das relações sociais, as formas dos atos de fala evoluem em consequência da interação verbal, e o processo de evolução reflete-se, enfim, na mudança das formas da língua”. (BAKHTIN, 2004, p. 124). 
Portanto, quando reconhecemos os princípios estruturalistas na teoria de Bakhtin, aceitamos também que ele os instaura para tratar das práticas, por meio da noção de gênero discursivo. Epistemologicamente, Bakhtin constitui procedimentos de objetivação parcial de sua ontologia, resguardando-a pela noção de dialogia. Tomada como princípio constitutivo da linguagem e da vida social, a dialogia ampara-se na assunção de que a unidade real da língua é o enunciado, uma entidade única e irrepetível, um acontecimento: os elos de uma cadeia infinita e imensa de relações responsivas ativas dos sujeitos no processo de comunicação. É possível, então, ler na obra de Bakhtin a antecipação de todos os elementos de uma relação dialética e dialógica entre estruturas e práticas, como se pode inferir da seguinte imagem sobre a dinâmica estruturante (BAKHTIN, 1997, p. 285): "[os] enunciados e o tipo a que pertencem, ou seja, os gêneros do discurso, são as correias de transmissão que levam da história da sociedade à história da língua". A metáfora das "correias de transmissão" recupera tanto os aspectos estruturais, implicados pela "correia" e por seus "eixos dentados", como o movimento, inclusive a agência.

De forma um tanto simplista, portanto, o modelo de Bakhtin poderia ser condensado no seguinte raciocínio: os enunciados são carregados de implicações subjetivas e eventícias irrecuperáveis, mas sempre se constituem em uma cadeia responsiva imensa e complexa. Essa cadeia acaba por produzir uma estabilidade parcial que se expressa sob a forma de gêneros, os quais, por sua vez, passam a constituir parcialmente os enunciados. Nesse mesmo sentido se formam as esferas sociais, passando também a ter efeitos constitutivos parcialmente estruturantes sobre o devir, ainda que este não esteja completamente subordinado às estruturas que se vão constituindo e desconstruindo nesse processo.

Nesse sentido, pode-se dizer que todas as abordagens em Análise do Discurso, em maior ou em menor grau, ecoam os elementos e as relações que Bakhtin define em sua proposta de análise objetiva da comunicação verbal. A dialogia constitutiva dos enunciados, sua materialidade, seu aparecimento em uma imensa rede de retomadas internas e externas, sua definição estrutural por meio de seu valor relacional, já estão, operacionalmente, presentes em sua obra, como se pode ver no trecho seguinte (BAKHTIN, 1997, p. 316, grifo nosso):

Um enunciado concreto é um elo na cadeia da comunicação verbal de uma dada esfera. As fronteiras desse enunciado determinam-se pela alternância dos sujeitos falantes. Os enunciados não são indiferentes uns aos outros, refletem-se mutuamente. São precisamente esses reflexos recíprocos que lhes determinam o caráter. O enunciado está repleto dos ecos e lembranças de outros enunciados, aos quais está vinculado no interior de uma determinada esfera comum da comunicação verbal. $O$ enunciado deve ser considerado acima de tudo como uma resposta a enunciados anteriores dentro de uma dada esfera [...]: refuta-os, confirma-os, completa-os, baseia-se neles, supõe-nos conhecidos e, de um modo ou de outro, conta com eles. Não se pode esquecer que um enunciado ocupa uma posição 
definida numa dada esfera da comunicação verbal relativa a um dado problema, a uma dada questão etc. Não podemos determinar esta posição sem correlacioná-la com outras posições. É por esta razão que o enunciado é repleto de reações-respostas a outros enunciados numa dada esfera da comunicação verbal. Estas reações assumem formas variáveis: podemos introduzir diretamente o enunciado alheio no contexto do nosso próprio enunciado, podemos introduzir-lhe apenas palavras isoladas ou orações que então figuram nele a título de representantes de enunciados completos. Nesses casos, o enunciado completo ou a palavra, tomados isoladamente, podem conservar sua alteridade na expressão, ou então se modificados (se imbuírem de ironia, de indignação, de admiração etc.); também é possível, num grau variável, parafrasear o enunciado do outro depois de repensá-lo, ou simplesmente referir-se a ele como as opiniões bem conhecidas de um parceiro discursivo; é possível pressupô-lo explicitamente; nossa reaçãoresposta também pode refletir-se unicamente na expressão de nossa própria fala - na seleção de recursos linguísticos e de entonações, determinados não pelo objeto de nosso discurso e sim pelo enunciado do outro acerca do mesmo objeto.

Em Bakhtin, a noção de prática está parcialmente indicada em suas definições de enunciado e de gêneros discursivos. A de estrutura, por seu turno, reside no seu relacionamento entre enunciados, gêneros e esferas, vinculadas acima pelo conceito de posição relacional, que equivale a valor e a diferença no estruturalismo. No trecho acima, a indicação da densidade dialógica dos enunciados, seus efeitos de interioridade e de exterioridade na cadeia verbal revela perceptivelmente a antecipação das explicações de Foucault $(1996 ; 2002)$ sobre enunciados e formações discursivas e de Bourdieu (1997) sobre estruturas estruturadas estruturantes e habitus. Nas seções seguintes, retomaremos apenas as noções de prática e de estrutura, no sentido de estabilizar suas condições de objetividade. Interessa-nos enfatizar que a abordagem estrutural é ainda necessária e produtiva, mesmo diante a incorporação da noção de acontecimento.

\section{A noção de estrutura na arqueologia de Michel Foucault}

A obra de Michel Foucault influenciou de diferentes maneiras as mais variadas áreas das Ciências Humanas. Seus estudos as desestabilizaram não apenas por mostrar certas complexidades de seus percursos constitutivos, mas também pela forte impressão que suas análises causaram sobre as subjetividades de seus pesquisadores. Condenado por seus adversários pelas muitas mudanças teórico-metodológicas de suas abordagens consecutivas, esse autor teve um objetivo constante e atualizado a cada obra. Seja com relação a métodos, a categorias ou mesmo a valores semânticos das terminologias adotadas, seu trabalho é sempre uma crítica 
da razão, suas racionalidades, seus aparatos e seus sujeitos. Como professor, pesquisador e escritor, sendo quase um arquétipo do sujeito moderno, Foucault faz, permanentemente, uma crítica da crítica (VEIGA-NETO, ano?, 28; 25): "O que o move é, no fundo, uma permanente suspeita; suspeita que se contorce e se volta até mesmo contra sua própria filosofia e sua intensa militância política, como se ele quisesse se libertar até de si mesmo". Essa suspeição permanente, entretanto, não parece significar que ele negue a necessidade da construção de regimes de verdade, mas sim que trabalhe sobre a desestabilização desses regimes, mesmo que sejam seus. É pela compreensão desse permanente movimento de esquiva que tentaremos apreender o uso da noção de estrutura em sua obra.

Contemporâneas do auge do movimento estruturalista, suas primeiras pesquisas históricas e epistemológicas desenvolveram um interesse especial pela crítica do documento, sendo, finalmente, sistematizadas em uma abordagem chamada de arqueologia (FOUCAULT, 2002). Com essa denominação, Foucault se afasta do estruturalismo, cuja aplicação não fora totalmente estranha a seus primeiros trabalhos, como ele mesmo admite. Reorganiza e reinventa seus dispositivos teórico-metodológicos, escapando à pressão de ter de se posicionar no debate entre intelectuais estruturalistas e marxistas ${ }^{12}$. Não lhe interessa compartilhar o peso do possível caráter ideológico de certas abordagens ligadas ao estruturalismo ontológico. Em sua sistematização arqueológica, Foucault passa a tratar os discursos como práticas e os enunciados como acontecimentos, mantendo, no entanto, um aparente viés estruturalista, visível em uma série de noções como as de formação discursiva, arquivo, sistema, regularidade, positividade, ordem, correlação.

Centrando-se na descrição de relações enunciativas muito parecidas com as que já comentamos a respeito do trabalho de Bakhtin, desenvolve-as em um estilo teórico enviesado, mas muito rico em relações temáticas, sempre recuperadas de suas pesquisas anteriores. Nesta seção, retomaremos apenas duas categorias que, uma vez decifradas, permitem mostrar a presença da noção de estrutura na arqueologia de Foucault. A primeira delas, que retoma em certa medida a ideia de esfera social como um sistema de gêneros discursivos e de cadeias de enunciados, é a categoria de formação discursiva (FOUCAULT, 2002, p. 43, grifo nosso):

No caso em que se puder descrever, entre um certo número de enunciados, [...] [um] sistema de dispersão, e no caso em que entre os objetos, os tipos de enunciação, os conceitos, as escolhas temáticas, se puder definir uma regularidade (uma ordem, correlações, posições, funcionamentos, transformações), diremos, por convenção, que se trata de uma formação discursiva.

Conforme vimos tratando os aspectos da abordagem estrutural nas discussões precedentes, podemos supor que a noção de formação discursiva não se refere a apenas uma estrutura ou a um quadro de diferenças somente, mas a um conjunto de estruturas dinamicamente correlacionadas. Em outras palavras, Foucault parece querer montar um dispositivo teórico-

${ }^{12}$ Essa situação é comentada por Dosse (1993) e por Gregolin (2004). 
metodológico que permita fazer o que Bakhtin diz ser impossível: uma estruturação do acontecimento enunciativo. Nessa leitura, a descrição das formações discursivas poderia ser equiparada a uma objetivação do devir, em cuja operacionalização o próprio autor prevê a descrição da formação de cada um dos seus elementos: dos objetos, dos tipos de enunciação, dos conceitos e das escolhas temáticas. É nessa empresa, que terminará por se dar de forma parcialmente circular, incompleta e ambígua, que emergirá o uso de um termo fundamental para os estudos do discurso, a dispersão: a regularidade resultante do relacionamento de descrições estruturais incompletas.

A proposta de Foucault, no entanto, só parece incoerente porque ele não a assume explicitamente. Seu objetivo não é absurdo, mas apenas impraticável; só é possível realizá-lo precariamente, por meio do relacionamento disperso de elementos de estruturas diferentes. Essa hermenêutica encontra amparo no exame do segundo conceito selecionado, a categoria de arquivo, marcadamente estrutural (FOUCAULT, 2002, p. 148, grifo do autor):

[...] temos na densidade das práticas discursivas sistemas que instauram os enunciados como acontecimentos (tendo suas condições e seu domínio de aparecimento) e coisas (compreendendo sua possibilidade e seu campo de utilização). São todos esses sistemas de enunciados (acontecimentos de um lado, coisas de outro) que proponho chamar de arquivo.

Nesse trecho, os enunciados são definidos, ao mesmo tempo, como "acontecimentos" e como "coisas" o que, nos termos de Bakhtin e de Eco, seria equivalente a eventos do devir permanente e a objetos estruturados ${ }^{13}$. Nessas condições, sistemas de enunciados seriam sistemas de sistemas: sistemas de objetos, sistemas de modalidades enunciativas, sistemas de conceitos e sistemas de escolhas temáticas. Por decorrência e de acordo com as discussões precedentes, dizer que as práticas discursivas são densas significa reconhecer que elas são estruturadas. Enfim, ao que tudo indica, a noção de arquivo em Foucault parece ser uma metáfora tridimensional para a concepção de uma estrutura de todas as estruturas: o conjunto das séries diacrônicas de todos os sistemas sincrônicos que compõem os sistemas de enunciados.

Além disso, nada pode ser mais estruturalista do que equiparar a história a esse móvel tão comum em escritórios, em bibliotecas e em repartições, com suas gavetas organizadas espacialmente, com seus documentos classificados cronologicamente, tematicamente, tipologicamente etc. Um arquivo pode ter o tamanho de quantos móveis se queira imaginar, e a qualidade de quantas ordenações se consiga conceber, interna e externamente ${ }^{14}$.

${ }^{13}$ Desde que se possa estar em acordo sobre a identidade dos comentários, suas condições e seu domínio de aparecimento e sua possibilidade e seu campo de utilização. A aparente diferenciação desses elementos parafrásticos diz respeito ao caráter enviesado que reputamos ao estilo foucaultiano.

${ }^{14}$ É tamanha a grandiloquência figurativa dessa metáfora epistemológica, que não seria estranho que esse conceito tenha sido mais um presente de Borges a Foucault: neste caso, como uma derivação da mítica biblioteca do autor argentino, que conteria todos os livros do mundo jamais escritos. 
À diferença do estruturalismo ontológico, no entanto, Foucault não quer reduzir tudo o que existe a uma origem estrutural mais profunda, mas o inverso disso. A noção foucaultiana de arquivo é a expansão das relações estruturais ao devir em si mesmo: cada acontecimento seria uma origem possível. Apesar da complexidade do raciocínio, julgamos que as explicações ontológico-epistemológicas de Bakhtin e de Eco, já referidas, permitem entender o que Foucault tenta (não) dizer em sua explicitação teórico-metodológica: um enunciado é um acontecimento singular dentro de uma imensa e complexa cadeia de enunciados; seu estudo se faz pela recuperação e pelo mapeamento, ainda que precário, das relações estruturais dos seus diversos sistemas de produção (suas condições de possibilidade).

Assim, apesar do desejo de afastar-se do estruturalismo, uma possibilidade de leitura de sua perspectiva arqueológica é concebê-la como um tratamento estrutural dos acontecimentos discursivos, seja como estruturas discursivas, seja como práticas discursivas estruturadas.

\section{A noção de estrutura na Análise do Discurso de Norman Fairclough}

A obra de Fairclough é profícua na produção de relações transdisciplinares, sempre focadas na integração de modelos teórico-metodológicos dos estudos linguísticos e das Ciências Sociais. Sua apropriação analítica das temáticas contemporâneas é sempre direcionada à interação da linguagem com o poder e à mudança social.

Em sua Teoria Social do Discurso (2001), Fairclough apresentou uma conjugação da análise linguística à teoria social, a qual acabou tornando-se paradigmática para o que hoje se conhece como Análise de Discurso Crítica (MAGALHÃES, 2005; 2001). Nessa versão, um modelo analítico tridimensional relacionava o estudo detalhado das propriedades linguísticas dos textos à avaliação das práticas sociais por meio do exame das práticas discursivas. Fairclough considerava que práticas e estruturas sociais relacionam-se dialeticamente. As práticas discursivas eram concebidas como a faceta discursiva das práticas sociais e definiamse como processos de produção, de distribuição e de consumo textuais. Tomadas como foco do trabalho analítico, uma vez que permitiam um acesso bastante direto ao estudo da mudança social pelo exame das mudanças linguísticas, sua análise apoiava-se na abordagem da gramática sistêmico-funcional de Halliday (1985).

Nesse modelo examinam-se os efeitos constitutivos das práticas discursivas sobre identidades, sobre relações sociais e sobre sistemas de conhecimento e de crença dos agentes envolvidos nos eventos discursivos. As marcas textuais relativas a elementos como vocabulário, padrões gramaticais e coesivos são associadas à mobilização de gêneros e de discursos e, consecutivamente, às características não discursivas dos espaços comunitários, institucionais e sociais dos eventos. Assim, as relações intertextuais e interdiscursivas estabelecidas e as marcas que produzem nos textos permitiriam avaliar os tipos de relações de poder que as práticas discursivas reproduzem ou transformam. Nesse aspecto, a abordagem de Fairclough refrata as perspectivas de Bakhtin e de Foucault tanto em relação às complexidades que as relações enunciativas podem ter, quanto às características de pulverização das relações de 
poder que podem ensejar. Tais relações são avaliadas por meio da localização da ideologia, concebida como sentido a serviço do estabelecimento de relações de poder, e da hegemonia, a produção ideológica de consenso, no âmbito do gerenciamento das práticas discursivas. A geração de padrões de uso da linguagem, como viés de análise do caráter das práticas sociais, encontra, na categoria de ordem de discurso, uma tentativa de sistematização mais abrangente das relações sociais por meio do exame dos processos discursivos. Fairclough define uma ordem de discurso como o conjunto total das práticas discursivas de um campo social, seja institucional, seja comunitário, isto é, como a faceta discursiva de uma ordem social.

A perspectiva teórico-metodológica dessa primeira sistematização foi, posteriormente, associada a uma reflexão ontológico-epistemológica na qual o autor se refere à vida (natural e social) como "um sistema aberto, em que qualquer evento é governado por 'mecanismos' operativos simultâneos" (CHOULIARAKI; FAIRCLOUGH, 1999, p. 19):

\begin{abstract}
As várias dimensões e níveis da vida (inclusive nos aspectos físicos, químicos, biológicos, econômicos, sociais, psicológicos, semiológicos e linguísticos) têm suas próprias estruturas distintivas, que possuem diferentes efeitos gerativos sobre os eventos através de mecanismos particulares. Como a operação de cada mecanismo é sempre mediada pela operação dos outros, nenhum mecanismo tem efeitos determinantes sobre os eventos e, por isso, os eventos são complexos e não podem ser previstos de modos simples como efeitos desses mecanismos.
\end{abstract}

É interessante observar que essa reflexão retoma, de certo modo, a assunção da noção de eventicidade de Bakhtin, mas descreve-a em termos estruturais ontológicos. Salvo melhor juízo, não fica claro se as estruturas são pensadas como dadas ou como postas, se são a busca da estruturação do real ou a aplicação de modelos estruturais hipotéticos. Neste momento, entretanto, nosso interesse diz respeito ao uso da noção de prática no trabalho de Fairclough e, como vimos acima, ele a considera como estruturada.

Em suma, Fairclough considera que as ordens sociais e as suas práticas, cujas orientações são variavelmente econômicas, políticas, pedagógicas podem ser avaliadas pelo exame de seus aspectos discursivos. Os modos pelos quais os textos são produzidos, distribuídos e consumidos permitem avaliar os tipos de conflitos e de consensos que organizam determinado espaço social. As maneiras pelas quais as cadeias de gêneros são constituídas, mantidas ou transformadas; a regulação dos discursos que são mobilizados, com suas metáforas, implícitos, estilos e vocabulários; e a relação dessas características discursivas a outros fatores não discursivos são formas de mensurar e de avaliar os modos de organização social, seus aspectos ideológicos e hegemônicos. Mudanças sociais estão sempre associadas a mudanças nos usos da linguagem, e o conceito de prática discursiva é o elemento-chave das análises.

Não há duvidas, portanto, quanto à manutenção da epistemologia estruturalista nas análises do discurso, de um modo geral, dada a sua referenciação em noções saussurianas, e na ADC, especificamente, que, além das fontes bakhtinianas e foucaultianas, apropria-se ainda 
de outras da linguística funcional e textual. Não há também, de fato, nenhum caráter militante nesse reconhecimento. Pelo contrário, reconhecer o caráter operacional dessa permanência teórica é apenas uma atitude teoricamente saudável. Sem eliminar outras influências e derivas epistemológicas que constituam as análises do discurso, reconhecer este solo é absolutamente necessário.

\section{REFERÊNCIAS}

BAKHTIN, M. Para uma filosofia do ato. Trad. Carlos Alberto Faraco. Manuscrito. s/d. . Estética da criação verbal. 3. ed. São Paulo: Martins Fontes, 1997 . Marxismo e filosofia da linguagem. 11. ed. São Paulo: Hucitec, 2004.

. Para uma filosofia do ato responsável. Trad. aos cuidados de Valdemir Miotello e Carlos Alberto Faraco. São Carlos: Pedro \& João Editores, 2010.

BENVENISTE, E. Problemas de linguística geral I I. Campinas: Pontes, 1989. . Problemas de linguística geral I. 4. ed. Campinas: Pontes, 1995.

BOURDIEU, P. Razões práticas: sobre a teoria da ação. Oeiras: Celta, 1997.

CHOULIARAKI, L; FAIRCLOUGH, Norman. Discourse in late modernity: rethinking critical discourse analysis. Edinburgh, England: Edinburgh University Press, 1999.

DOSSE, F. História do estruturalismo. v. 1. O campo do signo. Campinas: Ed. Unicamp, 1993.

ECO, U. A estrutura ausente. 7. ed. São Paulo: Perspectiva, 1997.

FAIRCLOUGH, N. Discourse and social change. New York, Longman, 2001.

FIORIN, J.L. Interdiscursividade e intertextualidade. In: BRAIT, Beth (org.). Bakhtin: outros conceitoschave. São Paulo: Contexto, 2006.

FOUCAULT, M. A ordem do discurso. São Paulo: Edições Loyola, 1996.

. A arqueologia do saber. 6. ed. Rio de Janeiro: Forense Universitária, 2002.

GREGOLIN, M. do R. Foucault e Pêcheux na análise do discurso: diálogos e duelos. São Carlos: ClaraLuz, 2004. 
HALLIDAY, M. A. K. An introduction to functional grammar. 2. ed. London, UK: British Library, 1985.

KOCH, I. G. V. Introdução à linguística textual: trajetória e grandes temas. São Paulo: Martins Fontes, 2004.

MAGALHÃES, I. Prefácio. In: FAIRCLOUGH, Norman. Discurso e mudança social. Brasília: Editora Universidade de Brasília, 2001. . Introdução: a análise de discurso crítica. Delta. v. 21. 2005. São Paulo: Educ (n. especial).

NEVES, M. H. de M. A gramática funcional. São Paulo: Martins Fontes, 2004.

PERINI, M. A. Princípios de linguística descritiva: introdução ao pensamento gramatical. São Paulo: Parábola Editorial, 2006.

VEIGA-NETO, A. Foucault \& a educação. Belo Horizonte: Autêntica, 2003. 